\title{
Type 1 tympanoplasty in pediatric patients: a review of 102 cases
}

\author{
Deniz Baklaci* (D, Ismail Guler, Ihsan Kuzucu, Rauf Oguzhan Kum and Muge Ozcan
}

\begin{abstract}
Background: The aim of this study was to investigate the success of type 1 tympanoplasty in pediatric patients with chronic otitis media, and to evaluate the prognostic factors that may influence its success.

Materials and methods: Medical records of 102 children aged between 8 and 18 years (46 female, 56 male) who underwent type 1 tympanoplasty for chronic tympanic membrane perforation between January 2010 and July 2017 were reviewed. Age, gender, condition of contralateral ear (unilateral, bilateral), type (central, marginal) and location of perforation (anterior, posterior, inferior), graft material (fascia, cartilage), pre- and post-operative hearing levels, mean air-bone gap (ABG), surgical approach (postauricular, endaural) and length of follow up were recorded.

Results: Anatomical and functional success (ABG $<20 \mathrm{dBHL}$ ) rates were $86.3 \%$ (88 patients) and $74.5 \%$ (76 patients) after a mean follow-up of $32 \pm 16.55$ months, respectively. The mean hearing improvement was $10.77 \pm 10.45 \mathrm{dBHL}$. The graft success rates were significantly higher in tragal cartilage group (95.1\%) than in temporalis fascia group (80.3\%) $(p=0.033)$. Graft success was negatively affected by contralateral perforation $(p=0.003)$. All patients with bilateral perforations and graft failure were in temporalis fascia group. Age, type and location of perforation and surgical approach did not influence graft success $(p>0.05)$.

Conclusion: Our results showed that type 1 tympanoplasty can be performed effectively in pediatric population regardless of age, location and type of perforation and surgical approach. Bilateral perforations are prone to reperforation, and should be treated with cartilage graft.
\end{abstract}

Keywords: Type 1 tympanoplasty, Children, Prognostic factors, Graft success, Hearing

\section{Background}

Tympanoplasty was popularized by Zollner and Wullstein [1] in the middle of 1950s. Today, the success rate of tympanoplasty still remains a considerable interest. There has been a particular attention to the outcomes of tympanoplasty in the pediatric age group since 1960s [2, 3]. In the literature, a success rate of tympanoplasties in children ranging from 35 to $94 \%[4,5]$. Numerous factors have been proposed for the reason of poorer tympanoplasty outcomes in children than in adults: higher frequency of upper respiratory infection and otitis media, poorer eustachian tube function and presence of hypertrophic adenoid tissue, and immaturity of the immune system [6-10]. Therefore, some authors do not propose tympanoplasty in pediatric age $[10,11]$. They advocate that eustachian tube

\footnotetext{
* Correspondence: doktorent@gmail.com

Numune Training and Research Hospital, Department of Otolaryngology, 931st Avenue 945st Street No:5/3 Çankaya, Ankara, Turkey
}

dysfunction results in inadequate ventilation to the middle ear, leading to the tympanic membrane (TM) perforation [7-10]. These results mitigating against delaying tympanoplasty in pediatric patients allows for the spontaneous closure of TM perforations. Another problem in pediatric tympanoplasty is thata narrow external auditory canal may complicate the surgery in some patients while postoperative dressings and care may be compelling and unpleasant, especially in uncooperative children.

Nevertheless, studies showed that tympanoplasty success rates in pediatric population were similar to adults $[6,12,13]$. The philosophy of performing tympanoplasty on the pediatric population is based on facts that cannot be disregarded. The presence of hearing loss in childhood has negative effects on the development of speech, language and learning skills. It has been showed that children with hearing loss have some difficulties with reaching their full academic potential [14]. Since

(c) The Author(s). 2018 Open Access This article is distributed under the terms of the Creative Commons Attribution 4.0 International License (http://creativecommons.org/licenses/by/4.0/), which permits unrestricted use, distribution, and reproduction in any medium, provided you give appropriate credit to the original author(s) and the source, provide a link to the Creative Commons license, and indicate if changes were made. The Creative Commons Public Domain Dedication waiver (http://creativecommons.org/publicdomain/zero/1.0/) applies to the data made available in this article, unless otherwise stated. 
children have an excellent cochlear reserve, they are more likely to benefit from tympanoplasty in terms of hearing improvement. On the other hand, the risk for a long-standing perforation isthat the squamous epithelium may enter the middle ear through the perforation and this may result in cholesteatoma formation in the middle ear cavity [15]. Therefore, closure of TM perforation prevents cholesteatoma formation and ossicular damage in the long-term. A successful tympanoplasty provides children a safe, non-draining and care-free ear and also the ability to participate in water activities and other social activities without restriction.

There are various factors that may affect the surgical success of tympanoplasty in children, such as age, the size and location of perforation, previous otological operations (ventilation tube, myringotomy, tympanoplasty), condition of the operated and contralateral ear (dry vs draining), presence of adenoid hypertrophy, function of the eustachian tube, choice of graft material, surgical technique and surgeon's experience [8-10, 16]. However, there is still a lack of certainty on which factors contribute to a successful closure due to inconsistencies in demographic and surgical parameters have been evaluated in the literature.

In this study, we aimed to investigate the surgical and functional outcomes of type 1 tympanoplasty in pediatric population and determine the factors influencing the success of tympanoplasty.

\section{Methods}

Medical records of 147 pediatric patients who underwent primary tympanoplasty in our clinic between January 2010 and July 2017 were reviewed. The casespresenting with wet ear, cholesteatoma, tympanosclerosis, ossicular chain erosion, combined with mastoidectomy or ossiculoplasty, and patients younger than 8 years old and older than 18 at the time of the surgery and whose first follow-ups were less than 12 months,were excluded from the study.

The study was approved by the local ethics committee (no: E-18-1907), and conducted in accordance with the ethical principles described by the Declaration of Helsinki. Prior written informed consent was obtained from the parents or guardians of the children who served as participants, and of participants 16 years or older, and assent form participants under 16 years of age.

For each patient we analyzed age, gender, condition of contralateral ear (unilateral/bilateral), type (central/ marginal) and location of the perforation (anterior/ posterior/inferior), graft material (temporal fascia/tragal cartilage), preoperative and postoperative hearing levels, surgical approach (postauricular/endaural), and length of follow-up. Patients were divided into two groups by age: $\leq 12$ years and $13-18$ years, as those that are thirteen years old and older are considered adolescents, while those twelve years old and younger are considered children [17].

Type of perforation was described as marginal in cases which the anulus was involved, otherwise it was described as central. Location of perforation categorized into three groups regarding its relation to handle of malleus: anterior, posterior and inferior.

The nasal cavity and nasopharynx were examined by nasal endoscopy. The patients with allergic rhinitis were treated with nasal steroids and antihistaminic drugs for at least two months, and the operation was performed following the evaluation of allergic rhinitis symptoms and nasal cavity examination after treatment. The patients with adenoid vejetation were treated with adenoidectomy, and the operation was performed after three months from adenoidectomy surgery.

All the children were operated witha microscope (Möller-Wedel Optical ${ }^{\circ}$; Hamburg, Germany) under general anesthesia. All tympanoplastieswere performed using the underlay technique with temporalis fascia or tragal cartilage through postauricular or endaural incision.

All the children underwent detailed preoperative and postoperative 6th month pure-tone audiometry (PTA) measurements at $0.5,1,2$ and $4 \mathrm{kHz}$ frequencies using an Interacoustic AC-40 (Middelfart, Denmark) clinical audiometer. Preoperative and postoperative air and bone conduction thresholds were measured for four frequencies. The air-bone gap (ABG) was calculated as the average difference between the air conduction and the bone conduction at $0.5,1,2$, and $4 \mathrm{kHz}$. A successful functional result wasdefined as a postoperative $A B G$ of $20 \mathrm{~dB}(\mathrm{~dB})$ or less [18].

The postoperative follow-up controls take place generally at hospital at the 1st, 3rd, 6th, and 12th months, and annually there after. The surgical performance is measured by otoscopic and microscopic examinations 12 months after the surgery.

Statistical data analysis was performed using SPSS 21 (SPSS Inc., IBM company, Chicago). Data was expressed as mean \pm standard deviation (S.D) and as proportion (\%). Chi-square test was used for comprising of categorical data. Wilcoxon and Mann-Whitney $U$ tests were used for non-parametric variables whereas independent and paired sample $\mathrm{t}$ test were used for parametric variables. The multivariate logistic regression analysis was used to identify independent predictors of functional success. A $p$ value $<0.05$ was accepted as statistically significant.

\section{Results}

A total of 102 patients (46 female, 56 male) with 102 operated ears (66 left, 36 right) who met the criteria mentioned above were included in this study. The mean 
length of follow-up was $32 \pm 16.55$ months (range 12 to 66 months).

The prognostic factors regarding age, statue of contralateral ear, location and type of perforation, graft material and surgical approach are given in Table 1.

The mean age was $14 \pm 2.10$, ranging from 8 to 18 years old. There were 28 patients $(27.4 \%)$ in the younger group and 74 patients $(78.6 \%)$ in the older group. The mean ages were $11.21 \pm 1.01$ for 12 years old and younger and $14.92 \pm 1.37$ for 13 years old and older. Graft success rates were $85.5 \%$ (24 ears) for 12 years old and younger and $86.5 \%$ (64 ears) for 13 years old and older. There was no statistically significant difference in the graft success rates between age groups $(p=1.000)$. The distribution of tympanoplasty outcomes by age was given in Fig. 1.

The overall anatomical success rate of tympanoplasty was $86.3 \%$ (88 ears) at the last visit. During the follow-up period, recurrent perforation occurred in $13.7 \%$ of patients (14 ears) (Table 2).73 patients (71.6\%) had unilateral perforation, 29 patients $(28.4 \%)$ had bilateral perforation. Graft success rates were 93.2\% (68 ears) in patients with unilateral perforations and 69.0\% (20 ears) in patients with bilateral perforations, and the difference was statistically significant $(p=0.003)$.

Of the 102 ears, 45 ears $(44.1 \%)$ perforations were anterior, $45(44.1 \%)$ were posterior, and $12(11.8 \%)$ were inferior. Graft success rates were $86.7 \%$ (39 ears) in

Table 1 Comparison of prognostic factors for surgical outcomes

\begin{tabular}{|c|c|c|c|}
\hline & $n$ & Graft success $(n, \%)$ & $p$ \\
\hline Younger group & 28 & $24(85.5)$ & \\
\hline ( $\leq 12$ ages $)$ & & & N.S. \\
\hline Older group & 74 & $64(86.5)$ & \\
\hline \multicolumn{4}{|l|}{ (13-17 ages) } \\
\hline Unilateral perforation & 73 & $68(93.2)$ & 0.003 \\
\hline Bilateral perforation & 29 & $20(69)$ & \\
\hline \multicolumn{4}{|l|}{ Location of perforation } \\
\hline Anterior & 45 & $39(86.7)$ & \\
\hline Posterior & 45 & $39(86.7)$ & N.S. \\
\hline İnferior & 12 & $10(83.3)$ & \\
\hline \multicolumn{4}{|l|}{ Type of perforation } \\
\hline Central & 77 & $68(88.3)$ & N.S. \\
\hline Marjinal & 25 & $20(80)$ & \\
\hline \multicolumn{4}{|l|}{ Graft material } \\
\hline Fascia & 61 & $49(80.3)$ & 0.033 \\
\hline Cartilage & 41 & $39(95.1)$ & \\
\hline \multicolumn{4}{|l|}{ Approach } \\
\hline Postauricular & 78 & $67(85.9)$ & N.S. \\
\hline Endaural & 24 & $21(87.5)$ & \\
\hline
\end{tabular}

N.S., ${ }^{*} p>0.05$ anterior perforations, $86.7 \%$ (39 ears) in posterior perforations, and $83.3 \%$ (10 ears) in inferior perforations. There was no statistically significant difference in the graft success rates between the location of perforations $(p=0.952)$.

Seventy seven ears $(75.5 \%)$ were with a central perforation and 25 ears (24.5\%) were marginal perforation. Graft success rate of central perforations was $88.3 \%$ (68 ears) and marginal perforations was $80.0 \%$ (20 ears). There was no statistically significant difference in the graft success rates between the type of perforations $(p=0.294)$.

Temporal fascia was used in 61 ears $(59.8 \%)$ and tragal cartilage was used in 41 ears (40.2\%). Graft success rate of fascia group was $80.3 \%$ (49 ears) and cartilage group was $95.1 \%$ (39 ears), and the difference was statistically significant $(p=0.033)$.

Seventy eight ears (76.5\%) were operated via postauricular approach, 24 ears $(23.5 \%)$ were operated via endaural. Graft success rate of postauricular group was 85.9\% (67 ears) and endaural group was $87.5 \%$ (21 ears). There was no statistically significant difference in the graft success rates between the type of surgical approach $(p=0.573)$.

The mean preoperative and postoperative bone conduction thresholds were $12.51 \pm 8.18 \mathrm{~dB}$ and $9.74 \pm$ $8.60 \mathrm{~dB}$, respectively, and the difference was statistically significant $(p<0.001)$. The mean preoperative and postoperative air conduction thresholds were $39.36 \pm$ $14.10 \mathrm{~dB}$ and $25.79 \pm 15.57 \mathrm{~dB}$, respectively, and the difference was statistically significant $(p<0.001)$. The mean preoperative and postoperative ABG were $26.85 \pm$ $9.47 \mathrm{~dB}$ and $16.08 \pm 10.46 \mathrm{~dB}$, respectively, and the difference was statistically significant $(p<0.001)$ (Table 3). The mean hearing improvement was $10.77 \pm$ $10.45 \mathrm{~dB}$. The postoperative ABG was less than $20 \mathrm{~dB}$ in 76 patients, and the functional success rate was $74.5 \%$ (Table 2).

\section{Discussion}

Success of pediatric tympanoplasty has been a topic of discussion for many years. In the literature, there are numerous studies that investigated it with quite variable results $[4,5,10,12]$. The disparity of outcomes in pediatric tympanoplasty is attributed to different definition of success and heterogenity of the patients included. In the present study, the success rate of pediatric tympanoplasty was $86.3 \%$, and this result is consistent with rates based on the literature. Factors such as age, location and type of perforation, surgical approach have no statistically significant effect on tympanoplasty outcomes. Status of contralateral ear and graft material influence the outcomes of tympanoplasty.

The timing of pediatric tympanoplasty is controversial. Improvement of eustachian tube function continues with 


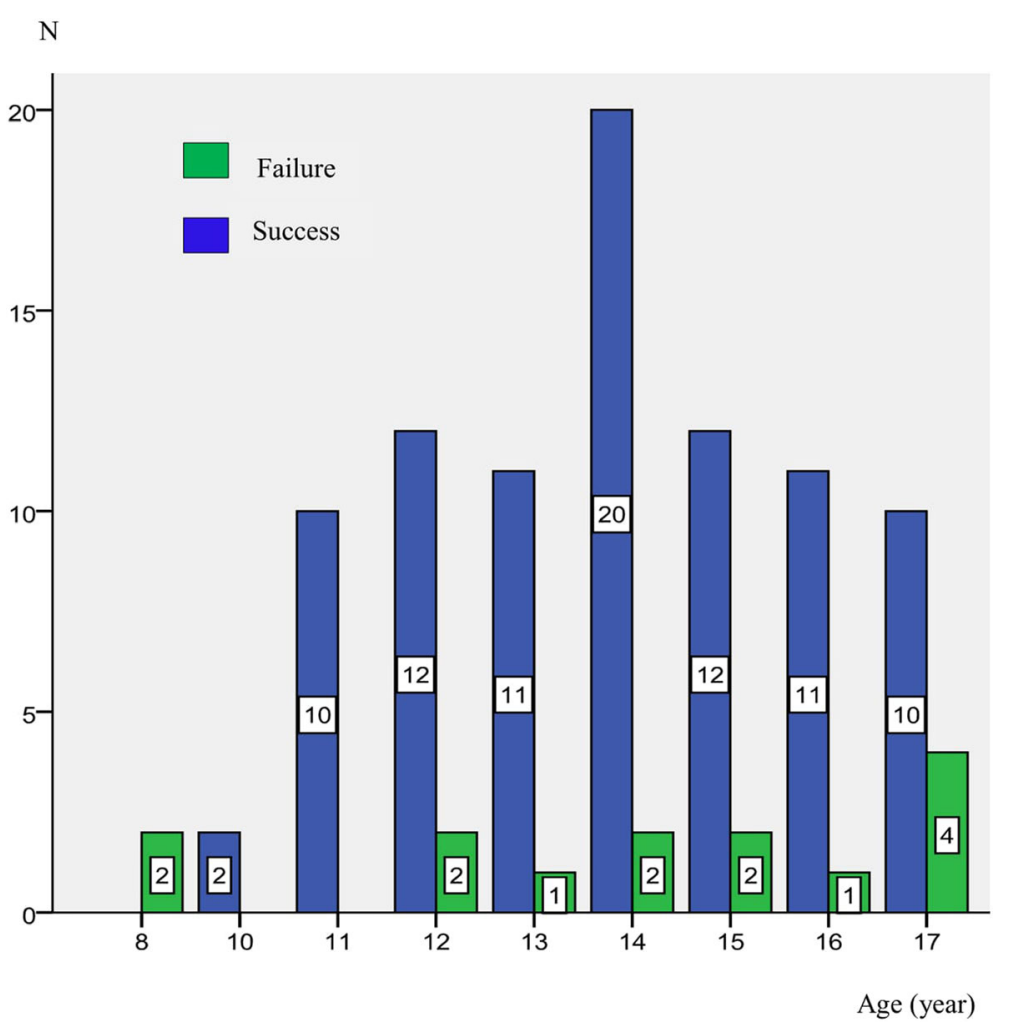

Fig. 1 Tympanoplasty outcomes by age. Shows the distribution of graft take results of patients according to age

aging children [19]. The reasons for the failure of the tympanoplasty results in early ages are thought to be inadequate function of the eustachian tube, weak immune system and recurrent upper respiratory tract infections $[6,8,20]$. There have been various suggestions by different authors regarding the age of the child before the surgery. Some recommended waiting until the ages of 6 [5], 7 [21] or 8 [9] for the operation while others observed more favorable results in children aged 9 [22], 10 [10] or 12 [8]. On the contrary, some authors declared that there was no correlation between age and surgical success [12, 22]. In a study [23], which included the surgical outcomes of tympanoplasty in 52 patients aged between 13 and 17 years old, the success rate was $80.8 \%$ similar to those found in adults. In our study, we compared two pediatric age groups (age 8-12 and age 13-18) in terms of tympanoplasty outcome, and found that tympanoplasty outcomes were favorable and similar in both groups $(p>0.05)$. Although a small number of patients were in the younger group, this is the first study to

Table 2 The anatomical and functional success

\begin{tabular}{lll}
\hline & $n$ & $\%$ \\
\hline Anatomical success & 88 & 86.3 \\
Functional success (<20 dBHL ABG) & 76 & 74.5 \\
\hline
\end{tabular}

$A B G$ air-bone gap compare the success of tympanoplasty between adolescent and childhood groups.

Eustachian tube function is an important factor affecting the success of surgery $[9,17]$. The status of contralateral ear can be a guide about eustachian tube dysfunction. Some authors [12] showed that the success rates of bilateral perforations decreased by half of unilateral perforations, and they proposed that high graft failures would be a result of severe eustachian dysfunction. In the present study, we used the status of contralateral ear as a predictor of eustachian tube function. There were five graft failures in unilateral group, and nine graft failures in bilateral group. Our results showed that the patients with unilateral perforation had higher graft success $(93.2 \%)$ than patients with bilateral perforations $(69 \%) \quad(p=0.003)$. Furthermore, we found that in all bilateral perforations that postoperative graft failure occurred, the temporal fascia had been used as graft material. We may state that when contemplating tympanoplasty in children with bilateral perforations, tragal cartilage should be considered firstly.

Location and type of perforation have been shownto be prognostic factors influencing surgical outcomes of tympanoplasty. The repair of anterior perforations might be technically difficult especially when the anterior canal is prominent, and blocks accessing the perforation. Some 
Table 3 Comparison of pre- and post-operative mean air-bone thresholds and ABG

\begin{tabular}{llll}
\hline & Pre-operative (dB \pm S.D.) & Post-operative (dB \pm S.D.) & $p$ \\
\hline Air conduction & $39.36 \pm 14.10$ & $25.79 \pm 15.57$ & $<0.001$ \\
Bone conduction & $12.51 \pm 8.1$ & $9.74 \pm 8.60$ & $<0.001$ \\
ABG & $26.85 \pm 9.47$ & $16.08 \pm 10.46$ & $<0.001$ \\
\hline
\end{tabular}

$d B$ decibel, $A B G$ air-bone gap, S.D. Standard deviation, $p<0.05$

authors [24] proposed that anterior perforations have a tendency to slow and poor healing in tympanoplasty while others [25] found the lowest failure rates in anterior perforations. Some authors [9], on the other hand, did not find any correlation between the location of perforation and graft success. We also did not find a significant correlation between surgical outcome and site of perforation $(p>0.05)$.

Graft success rates were observed to be significantly lower in marginal perforations compared to central perforationsin some studies [5] even though some authors [26] did not find a significant correlation between type of perforation and surgical success. In the present study, even though graft failure was more common in marginal perforations, we did not find any statistically significant relationship between type of perforation and surgical outcome $(p>0.05)$. Marginal perforations have a tendency tolead to cholesteatoma development, which results in ossicular chain erosion and hearing loss, hence it may be stated that a successful tympanoplasty in pediatric patients may prevent the complications associated with a long-term marginal perforation.

Temporalis fascia and tragal cartilage grafts have been most commonly usedin tympanoplasty for many years. Tragal cartilage is strong, thick and easy to place compared to temporal fascia. In a study by Ozbek et al. [27] a higher success rate was observed in the use of tragal cartilage compared to temporal fascia in type 1 pediatric tympanoplasty. In concordance with their results, we found a significantly higher rateof graft success in cartilage group (95.1\%) ( $p=0.033)$.

In our clinic, postauricular and endaural approaches were performed mostly. Halim et al. [28] compared the success rates of postauricular and endaural approach, and foundno statistically significant difference between two approaches. In this study, $76.5 \%$ of operations were performed via the postauricular approach while the rest were performed via the endaural approach. We did not find any correlation between success rate and surgical approach and the findings shows that both two techniques can be performed safely in pediatric patients.

Tympanoplasty is performed to achieve an intact tympanic membrane and hearing improvement. In our study, postoperative ABG significantly decreased compared to preoperative ABG $(p<0.001, p<0.001$, respectively). Previous studies reported a postoperative mean hearing gain up to $12 \mathrm{~dB}$ and a functional success rate ranging from 50 to $88 \%$ depending on the definition for improvement $[4-6,10,12,25,27]$. Our results were concordant with the literature.

Our study has some limitations. This is a retrospective study and the records of patients obtained from medical charts may be inaccurate or missing. Moreover, only postoperative $6^{\text {th }}$ month hearing results were investigated in our study. However, Future studies with longer follow-up period are needed to support our results.

\section{Conclusion}

In conclusion, we believe that type 1 tympanoplasty can be performed effectively in pediatric population regardless of age, location and type of perforation and surgical approach. Early tympanoplasty has an excellent potential for restoring hearing function and may prevent future complications and deterioration associated with long-term perforations. Bilateral perforations are prone to reperforation, and should be treated with cartilage graft.

\section{Abbrevations \\ ABG: Air-Bone gap; dB: Decibel; N.S: Non-significant; PTA: Pure Tone Audiometry; S.D.: Standard deviation; TM: Tympanic membrane}

\section{Acknowledgements}

Not applicable.

Funding

The author(s) received no specific funding for this work.

Availability of data and materials

The datasets used and analyzed during this study are available from the corresponding author on reasonable request.

Authors' contributions

DB: Conception, design, writer, IG: Data collection, design, IK: Literature review, design, ROK: Analysis and interpretation, MO: Supervision, critical review. All authors read and approved the final manuscript.

Ethics approval and consent to participate

The study was approved by the ethics committee of Ankara Numune Training and Research Hospital (no: E-18-1907), and conducted in accordance with the ethical principles described by the Declaration of Helsinki. An informed consent was obtained from all participating subjects prior to surgery.

Prior written informed consent was obtained from the parents or guardians of the children who served as participants, and of participants 16 years or older, and assent form participants under 16 years of age.

Consent for publication

Not applicable. 


\section{Competing interests}

The authors declare that they have no competing interests.

\section{Publisher's Note}

Springer Nature remains neutral with regard to jurisdictional claims in published maps and institutional affiliations.

Received: 6 August 2018 Accepted: 25 October 2018

\section{Published online: 06 November 2018}

\section{References}

1. Wullstein H. Theory and practice of tympanoplasty. Laryngoscope. 1956; 66(8):1076-93.

2. Gans H. Tympanoplasty in children. Arch Otolaryngol. 1963;77:350

3. Pyman C. Signposts to successful tympanoplasty, With special reference to children. J Otolaryngol Soc Aust. 1964;1:233-47.

4. Lau T, Tos M. Tympanoplasty in children. An analysis of late results. Am J Otol. 1986;7(1):55-9.

5. Kessler A, Potsic WP, Marsh RR. Type 1 tympanoplasty in children. Arch Otolaryngol Head Neck Surg. 1994;120(5):487-90

6. Bluestone CD, Cantekin El, Douglas GS. Eustachian tube function related to the results of tympanoplasty in children. Laryngoscope. 1979;89(3):450-8.

7. Berger G. Myringoplasty in children. J Laryngol Otol. 1974;88:1223-36.

8. Raine C, Singh S. Tympanoplasty in children: a review of 472 cases. Ann Otol Rhinol Laryngol. 1980;89:331-4.

9. Koch WM, Friedman EM, McGill TJ, Healy GB. Tympanoplasty in children: the Boston Children's Hospital experience. Arch Otolaryngol Head Neck Surg. 1990;116(1):35-40.

10. Shih L, de Tar T, Crabtree JA. Myringoplasty in children. Otolaryngol Head Neck Surg. 1991;105(1):74-7.

11. Lancaster J, Makura Z, Porter G, McCormick M. Paediatric tympanoplasty. J Laryngol Otol. 1999;113(7):628-32.

12. Caylan R, Titiz A, Falcioni M, De Donato G, Russo A, Taibah A, et al. Myringoplasty in children: factors influencing surgical outcome. Otolaryngol Head Neck Surg. 1998;118(5):709-13.

13. Collins WO, Telischi FF, Balkany TJ, Buchman CA. Pediatric tympanoplasty: effect of contralateral ear status on outcomes. Arch Otolaryngol Head Neck Surg. 2003;129(6):646-51.

14. Rapin I. Conductive hearing loss effects on children's language and scholastic skills: a review of the literature. Ann Otol Rhinol Laryngol. 1979;88(5_suppl):3-12.

15. Schuknecht HF. Cholesteatoma. Pathology of the Ear. 2nd ed. Philadelphia: Lea \& Febiger; 1993. p. 204-206.

16. Manning SC, Cantekin El, Kenna MA, Bluestone CD. Prognostic value of eustachian tube function in pediatric tympanoplasty. Laryngoscope. 1987;97(9):1012-6.

17. Panel SA. Referral to pediatric surgical specialists. Pediatrics. 2014;133(2):350-6.

18. Balkany TA, Gates GA, Goldenberg RA, Meyerhoff WL, House JW, SURG OHN. Committee on hearing and equilibrium guidelines for the evaluation of results of treatment of conductive hearing loss. Otolaryngol Head Neck Surg. 1995;113(3):186-7.

19. Bylander A, Tjernström Ö. Changes in Eustachian tube function with age in children with Normal ears: a Longiudinal study. Acta Otolaryngol. 1983:96(5-6):467-77.

20. Glasscock ME. Symposium: contraindications to tympanoplasty: II. An exercise in clinical judgment. Laryngoscope. 1976;86(1):70-6.

21. MacDonald RR, Lusk RP, Muntz HR. Fasciaform myringoplasty in children. Arch Otolaryngol Head Neck Surg. 1994;120(2):138-43.

22. Carr MM, Poje CP, Nagy ML, Pizzuto MP, Brodsky LS. Success rates in paediatric tympanoplasty. J Otolaryngol Head Neck Surg. 2001;30(4):199.

23. Rodrigues J, Sousa AC, Gomes A, Gomes P, Mexedo A, Fonseca R. Type I Tympanoplasty in adolescence: prognostic factors and surgical outcomes. Small. 2017;25(16):30.8

24. Kumar S, Acharya A, Hadjihannas E, Panagamuwa C, McDermott AL. Pediatric myringoplasty: definition of "success" and factors affecting outcome. Otol Neurotol. 2010;31(9):1417-20.

25. Castro O, Pérez-Carro AM, Ibarra I, Hamdan M, Meléndez JM, Araujo A, et al. Myringoplasties in children: our results. Acta Otorrinolaringol (English Edition). 2013;64(2):87-91.
26. Rozendorn N, Wolf M, Yakirevich A, Shapira Y, Carmel E. Myringoplasty in children. Int J Pediatr Otorhinolaryngol. 2016;90:245-50.

27. Ozbek C, Çiftçi O, Tuna EEU, Yazkan Ö, Ozdem C. A comparison of cartilage palisades and fascia in type 1 tympanoplasty in children: anatomic and functional results. Otol Neurotol. 2008;29(5):679-83.

28. Halim A, Borgstein J. Pediatric myringoplasty: postaural versus transmeatal approach. Int J Pediatr Otorhinolaryngol. 2009;73(11):1580-3.

\section{Ready to submit your research? Choose BMC and benefit from:}

- fast, convenient online submission

- thorough peer review by experienced researchers in your field

- rapid publication on acceptance

- support for research data, including large and complex data types

- gold Open Access which fosters wider collaboration and increased citations

- maximum visibility for your research: over $100 \mathrm{M}$ website views per year

At $\mathrm{BMC}$, research is always in progress.

Learn more biomedcentral.com/submissions 